\title{
PESQUISA COM O COTIDIANO
}

\author{
Carlos Eduardo Ferraço*
}

\begin{abstract}
RESUMO: Este texto trata do tema da pesquisa "com" o cotidiano. O interesse é provocar uma permanente abertura para a reflexão e o debate sobre o cotidiano e a pesquisa com o cotidiano, e não fechar a questão com uma proposta sistemática. Vale-se dos estudos desenvolvidos em escolas públicas do Estado do Espírito Santo no período de 1999 a 2004, cujo principal objetivo foi desencadear, entre os praticantes do cotidiano escolar, práticas de intervenção nos "currículos" e na "formação continuada", assumidos como processos complexos que se interpenetram em meio às redes de saberesfazeres tecidas e partilhadas pelos sujeitos das escolas. Podemos inferir, a partir das pistas encontradas, que o cotidiano exige dos pesquisadores em educação outras possibilidades teórico-metodológicas, diferentes daquelas herdadas da modernidade, para superar o aprisionamento do cotidiano em categorias prévias e assegurar a impossibilidade de usarmos o singular para tratar da diversidade que se manifesta na vida.
\end{abstract}

Palavras-chave: Pesquisa com o cotidiano. Redes de saberesfazeres. Currículo e formação continuada.

\section{RESEARCH WITH THE QUOTIDIAN}

ABSTRACT: This text explores the research "with" the quotidian. It aims to provoke a permanent opening to reflection and debate about the quotidian and the research with the quotidian, instead of closing the subject with a systematic proposal. It uses the studies developed in public schools from the State of Espírito Santo between 1999 and 2004. Their main objective was to provoke, in the school quotidian practitioners, intervention practices on the curriculum and continued formation, assumed as complex processes that interpenetrate the knowledge-doing networks woven and shared by the

\footnotetext{
* Doutor em Educação e professor do Programa de Pós-graduação em Educação da Universidade Federal do Espírito Santo (UfEs).E-mail: ferraco@uol.com.br
} 
school subjects. Based on the evidences found, we can infer that the quotidian requires that education researchers bring forth theoreticalmethodological possibilities different from those inherited from modernity to overcome the intention to lock the quotidian in pre-established categories and guarantee the impossibility of using the singular to deal with the diversity that manifests itself in life.

Key words: Research with the quotidian. Knowledge-doing networks. Curriculum and continued formation.

\section{Introdução}

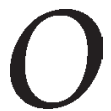

texto em questão é uma tentativa de discursar sobre a pesquisa "com" o cotidiano. Ao contrário da intenção de fechar a questão com uma proposta sistemática, nosso interesse reside na idéia de provocar uma abertura para a reflexão e o debate sobre o cotidiano e para a pesquisa com o cotidiano.

Para tanto, tomamos como referência pesquisas por nós desenvolvidas em escolas públicas do Espírito Santo no decorrer dos anos de 1999 a 2004, ${ }^{1}$ que envolveram diferentes sujeitos que praticam (Certeau, 1994) as escolas. Desse modo, um primeiro aspecto que destacamos está no fato de considerarmos como sujeitos das pesquisas com o cotidiano todos aqueles que, de modo mais visivel ou mais sutil, deixam suas marcas nesse cotidiano, isto é, os sujeitos das pesquisas com o cotidiano são: alunos, ${ }^{2}$ professoras, mães, vigias, serventes e tantos outros que "vivem" as escolas. ${ }^{3}$

$\mathrm{O}$ objetivo principal das pesquisas foi desencadear, entre esses sujeitos, processos de intervenção nos "currículos" e na "formação continuada", a partir das redes de saberesfazeres (Alves, 2001) tecidas e partilhadas entre eles. Nossas andanças pelas escolas nos têm proporcionado inúmeras possibilidades de trabalho com "diferenças culturais" (Bhabha, 1998) que expressam a complexidade (Morin, 1990) dos fazeressaberes cotidianos.

Assim, com nossas pesquisas, buscamos escutar os sujeitos das escolas para, a partir dessa escuta e com eles, fortalecer processos contra-hegemônicos de políticas educacionais cotidianas, como nos sugere Santos (2000), voltadas para a "formação continuada" e o "currículo", tendo como protagonistas os sujeitos que praticam a realidade (Certeau, 1994). 
Com isso, no que se refere à formação continuada, estivemos interessados nos processos cotidianos dessa formação que burlavam o planejamento sistemático e que aconteciam em diferentes espaçostempos das escolas.

No que diz respeito ao currículo, nosso interesse esteve voltado para o que alguns autores chamam de currículo praticado (Oliveira, 2003), ou curriculos em redes (Alves, 2001), ou currículo realizado (Ferraço, 2003), ou ainda, currículo real, como é o caso de Sacristán (1995, p. 86), que afirma:

Uma análise refinada da realidade escolar e das práticas cotidianas torna claro que aquilo que os alunos aprendem no contexto escolar - e aquilo que deixam de aprender - é mais amplo que a acepção de currículo como especificação de temas e conteúdos de todo tipo. Isto é, o currículo real é mais amplo do que qualquer "documento" no qual se reflitam os objetivos e planos que temos. Na situação escolar se aprendem mais coisas, dependendo da experiência de interação entre alunos e professores, ou entre os próprios (...) dependendo das atividades concretas desenvolvidas. Por isso se diz que o currículo real, na prática, é a conseqüência de se viver uma experiência e um ambiente prolongado que propõem - impõem - todo um sistema de comportamento e de valores, e não apenas de conteúdos de conhecimentos, a assimilar. Essa é a razão pela qual aquele primeiro significado de currículo como documento ou plano explícito se desloca para um outro, que considere a experiência real do aluno na situação de escolarização.

Em nossas análises, currículo não se reduz à declaração de áreas, conteúdos e metodologias, mas, como diz Sacristán (ibidem), pressupõe a soma de todo tipo de aprendizagens e de ausências que os alunos obtêm como conseqüência de estarem sendo escolarizados. Pensar os currículos de uma escola implica, então, viver seu cotidiano, o que inclui, além do que é formal, e tradicionalmente estudado, toda a dinâmica das relaçóes estabelecidas. Sacristán, ao destacar Stenhouse (1984, p. 27), assume:

Uma coisa é o currículo considerado uma intenção, um plano ou uma prescrição que explica o que desejaríamos que ocorresse nas escolas e outra o que existe nelas, o que realmente ocorre em seu interior. O currículo tem de ser entendido como cultura real que surge de uma série de processos, mais que como objeto delimitado e estático que se pode planejar e depois implantar. (1995) 
Ao discutir os currículos praticados no cotidiano, Oliveira (2003, p. 68) observa:

É com Certeau que vamos, mais uma vez, buscar a compreensão das formas de criação de alternativas curriculares, tentando evidenciar as "artes de fazer" daqueles a quem foi reservado o lugar da reprodução. (...) O cotidiano (...) aparece como espaço privilegiado de produção curricular, para além do previsto nas propostas oficiais.

Por último, também partimos da idéia de que a formação continuada e os currículos praticados são processos cotidianos intrinsecamente enredados, que se determinam mutuamente, não havendo como diferenciá-los, pensá-los de forma isolada, em meio às tessituras e partilhas das redes cotidianas de saberesfazeres.

De modo mais amplo, e aí se coloca uma outra questão de fundo para nós, cada vez tem sido mais difícil, nas redes cotidianas tecidas pelos sujeitos das escolas, identificar com nomes (tais como currículo, planejamento, avaliação, ensino, aprendizagem...) o que acontece nas escolas. Se nos cursos de formação estas palavras implicam teorias, em autores que escrevem e publicam livros sobre esses temas, nas redes cotidianas, tais palavras perdem seu poder de objetividade para identificar esta ou aquela situação. Ou seja, quando pensamos com o cotidiano das escolas, encontramos dificuldades em responder quando é que acontece, por exemplo, o planejamento, a avaliação, a aprendizagem, o ensino, entre outras tantas questóes. De fato, se nos situamos em meio às redes cotidianas das escolas, e com os sujeitos, a resposta para essas questôes é uma só: acontece tudo ao mesmo tempo e com todos!

Que estamos chamando de cotidiano e de pesquisa com o cotidiano?

Uma questão de fundo que se coloca em nossos estudos é o que estamos entendendo por cotidiano e, por efeito, o que significa a idéia de pesquisa com o cotidiano. Assim, em nossas leituras temos tentado problematizar as discussóes dos autores que se dedicam ao estudo do cotidiano, ${ }^{4}$ no sentido de trazer à cena não a condição de adoção de categorias e/ou estruturas de análise, mas, pelo contrário, a tentativa de pensar o cotidiano e a pesquisa com o cotidiano a partir de outras possibilidades. Como tenho defendido (2003, p. 162): 
De modo geral, uma metodologia de análise a priori nega a possibilidade do "com", do "fazer junto". Resulta em uma metodologia que antecede, que pensa antes o que poderá acontecer. Possível, mas não passam de previsões, como as do tempo...

A identificação objetiva de "categorias" e/ou "temas" de análise dos cotidianos só é possível, só tem sentido em estudos e pesquisas "sobre" os cotidianos. Pesquisar "sobre" traz a marca da separação entre sujeito e objeto. Traz a possibilidade de identificarmos o cotidiano como objeto em si, fora daquele que o estuda, que o pensa ao se pensar. Traz a marca do singular, do identificável em sua condição de objeto.

Pesquisar "sobre" aponta a lógica da diferença, do controle. Resulta no sujeito que domina, ou crê dominar, o objeto. Um "sobre" o outro, que "encobre", que se coloca "por cima" do outro sem entrar nele, sem o "habitar". Pesquisar "sobre" sugere a intenção de poder falar do outro a partir do outro, isentando-nos desse outro, colocando-nos separado desse outro.

De fato, temos em conta que, qualquer tentativa de sistematização de um conceito de cotidiano implica, fatalmente, seu engessamento. E aí está nosso maior desafio: Qual a legitimidade no uso de estruturas para falar de algo que é efêmero, incontrolável, caótico e imprevisível? Qual o sentido em extrair conceitos, atribuir classificações, estabelecer relaçôes hierárquicas, propor estruturas conceituais ao permanente devir cotidiano?

Se conceitos, categorias e estruturas se mostram como elementos operacionais nas pesquisas sobre a vida cotidiana, isto é, facilitam nossas análises e evocam um certo ar de academia, penso que acabamos pagando um preço alto por isso, à medida que nossas análises ficam confinadas aos limites que essas alternativas metodológicas nos impõem.

Então, como escapar do aprisionamento teórico das categorias ou das estruturas em nossas pesquisas? Como superar o engessamento da vida cotidiana em nossos textos? Não tenho respostas fechadas para estas questôes. As pistas que tenho tentado seguir têm emergido de nossas andanças pelas escolas. Logo, são conseqüências de nossas conversas, de nossas ações com os sujeitos cotidianos das escolas.

Um primeiro aspecto que temos tentado pensar se coloca na própria condição da vida vivida no cotidiano. Assim, em vez de um sistema formal e a priori de categorias, conceitos, estruturas, classificaçôes, ou outras formas de regulação, de ordenação exterior à vida cotidiana; temos considerado a possibilidade de pensar o cotidiano como redes de fazeressaberes tecidas pelos sujeitos cotidianos. 
Assim como as redes de saberesfazeres não se limitam ao território das escolas, também os sujeitos que as tecem não se reduzem aos sujeitos que lá estão por ocasião da realização das pesquisas. Como já dito, estamos considerando sujeitos potenciais de nossas pesquisas todos aqueles que, de forma mais direta ou indireta, estão envolvidos na tessitura e partilha das redes cotidianas.

Outro aspecto a ser destacado tem por objetivo descaracterizar a idéia de redes de fazeressaberes como algo que acontece no cotidiano, como uma dada característica ou propriedade do cotidiano. Consideramos cotidiano o próprio movimento de tessitura e partilha dessas redes. As redes não estão no cotidiano. Elas são o cotidiano!

Com isso, assumimos que qualquer tentativa de análise, discussão, pesquisa ou estudo com o cotidiano só se legitima, só se sustenta como possibilidade de algo pertinente, algo que tem sentido para a vida cotidiana, se acontecer com as pessoas que praticam esse cotidiano e, sobretudo, a partir de questôes e/ou temas que se colocam como pertinentes às redes cotidianas. Isto posto, precisamos considerar então que os sujeitos cotidianos, mais que objetos de nossas análises, são, de fato, também protagonistas, também autores de nossas pesquisas. Como defendi em outra ocasião (2003, p. 168):

Uma das coisas que temos aprendido e tentado garantir em nossos estudos "com" os cotidianos escolares é assumir os sujeitos cotidianos não só como sujeitos da pesquisa, mas, também, como nossos autoresautoras, reconhecidos em seus discursos, do mesmo modo como assumimos Najmanovich, Alves, Garcia, Certeau, Giard, Santos, Ginzburg, Oliveira, Esteban, Lefebvre... ou seja, os textos e discursos elaborados e compartilhados por esses sujeitos cotidianos da pesquisa precisam ser pensados não como citações e/ou exemplos dos discursos das autorasautores que estudamos nas academias, mas como discursos tão necessários, legítimos e importantes quanto estes.

Se consideramos a importância de dialogarmos com autores como Lefebvre, Garcia, Alves, Certeau, entre outrosoutras, também precisamos considerar a importância de esse diálogo ser ampliado, envolvendo aqueles que vivem, convivem, inventam, usam, praticam, habitam, ocupam, estão, nesses cotidianos. Isso, não por uma questão de "boa vontade" ou "gratidão", mas por uma condição de as pesquisas "com" os cotidianos não se tornarem estéreis, tediosas, soníferas ou, no máximo, como as propriedades da água: insípida, incolor e inodora. Ainda aqui, não se trata de usar fragmentos, trechos, das falas desses sujeitos como ilustrações do nosso discurso, assim 
como fazemos com os discursos dos teóricos legitimados pela academia. Trata-se de entender que também aqueles que vivem, de fato, esses cotidianos são os legítimos autoresautoras dos discursos "com" os cotidianos.

Outro aspecto a ser por nós considerado vai ao encontro dos movimentos de tessitura e partilha dessas redes. Questóes, temas, objetos de análise só se sustentam na perspectiva da pesquisa com o cotidiano quando se mostram como envolvidas, como inerentes aos processos de tessituras das redes que estão sendo tecidas pelos sujeitos cotidianos. Porque sempre tecidas junto com outras questōes, são sempre questôes complexas (Morin, 1994). Qualquer imposição temática, qualquer desconsideração com relação às questões que estão sendo tecidas pelos sujeitos resulta em "descredenciamento" (que na maioria das vezes não é verbalizado) de nossas pesquisas pelos sujeitos cotidianos.

Em nossas conversas com nossos orientandos temos argumentado em favor dessa questão. Por vezes, surgem projetos ou propostas de pesquisas que não tomam como base a complexidade das redes cotidianas tecidas pelos sujeitos das escolas e, mais que isso, trazem as marcas da modernidade expressas, por exemplo, na lógica do bem e do mal, certo ou errado, como nos títulos: "Quais as vantagens e desvantagens..."; "Quais os limites e possibilidades..."; "Que mecanismos facilitam ou dificultam..."; e outros. Há ainda, dentro dessa lógica, sintomas de busca por um procedimento-padrão, normativo, ideal, como nos títulos: "Como intervir..."; "Como avaliar..."; "Que procedimentos são necessários...".

De modo geral, essas propostas, entre tantas outras, distanciamse das redes tecidas no cotidiano das escolas e confinam-se em modelos teóricos que têm como pressupostos a busca pelas causas primeiras dos fatos e pela essência das coisas e dos sujeitos, reforçando, quase sempre, naturalizações com relação à escola e, por efeito, à educação. Não são raras as discussões que partem de idéias como: "Os professores estão desmotivados para ensinar", "Os alunos só querem saber de notas, não se interessam pelo conhecimento", entre outras. Linhares \& Garcia (2001, p. 43) abordam essa questão ao afirmarem:

Quem não ouve e não faz comentários sobre as escolas? Se bem atentarmos para estas opiniōes, veremos que elas, algumas vezes, se aproximam de conclusões fechadas que trancam a escola dentro dela mesma, acabando por deixar escapar a complexidade com que a vida nela se manifesta.

Quem de nós não ouviu expressões como estas? "Na escola não se ensina nem se aprende o que a vida requer." "A escola está cada vez pior" (...). 
Sem pretender discutir o quanto de erros e acertos estas afirmações contêm - esforço que julgamos sem sentido -, preferimos atentar para sua recorrência, que vai conquistando uma concordância generalizada que facilita seu deslizamento para um terreno das "evidências", pronto a selar consensos, avalizadores de convicções e certezas.

Falar dos perigos das unanimidades - sempre falsas e burras - não significa só lembrar Nelson Rodrigues, mas, sobretudo, cumpre o ofício de reiterar que o lugar da pesquisa e dos pesquisadores apenas se aproxima de um campo de conhecimento que o justifica quando se faz pelo exercício da resistência aos slogans e às certezas, mesmo quando estas estão respaldadas por extensas, intensas e autorizadas concordâncias e consensualidades.

Entendemos que uma das razões que vêm obstruindo o desenvolvimento da reflexão educativa no Brasil é, justamente, o temor de estremecer um mundo rígido de certezas. Estas certezas vêm se alojando nos trabalhos de pesquisa educacional, como um tipo de a priori percorrendo, subterraneamente, todas as etapas de seu desenvolvimento. Cada vez que caímos nestas armadilhas, a pesquisa confirma o já sabido e perdem-se, coletivamente, oportunidades para revelar e afirmar a complexidade do campo educacional.

Uma outra pista que estamos seguindo tem a ver com o fato de que nossa busca por tentar entender o que acontece no cotidiano das escolas e, sempre que convidado, tentar ajudar aos que lá estão, durante esses anos de pesquisa, traz as marcas das histórias por nós vividas na vida e na educação. Como defendi em outro texto (2003), em nossas pesquisas com o cotidiano das escolas estamos sempre em busca de nós mesmos, de nossas histórias de vida, de nossos "lugares", tanto como alunos que fomos quanto como professores que somos. Estamos, de alguma forma, sempre retornando a esses nossos "lugares" (Lefebvre, 1991), "entre-lugares" (Bhabha, 1998), "não-lugares" (Augé, 1994), de onde, de fato, penso que nunca saímos.

Assim, ao nos assumirmos como envolvidos na tessitura do "nosso" objeto de estudo, coloca-se para nós a impossibilidade de pesquisar ou de falar "sobre" os cotidianos das escolas. Como propus no texto já referido (2003, p. 160-161):

Se estamos incluídos, mergulhados, em nosso objeto, chegando, às vezes, a nos confundir com ele, no lugar dos estudos "sobre", de fato, acontecem os estudos "com" os cotidianos. Somos, no final de tudo, pesquisadores de nós mesmos, somos nosso próprio tema de investigação. Então, em nossos estudos "com" os cotidianos das escolas, no lugar de perguntas como: que 
significa essa atitude? Que quer dizer esse cartaz? Que significa esse texto? Qual o sentido dessa fala? Devemos perguntar: que leituras "eu” faço desse cartaz, texto ou fala?

Assim, em nossos estudos "com" os cotidianos das escolas, há sempre uma busca por nós mesmos. Apesar de pretendermos, nesses estudos, explicar os "outros", no fundo estamos nos explicando. Buscamos nos entender fazendo de conta que estamos entendendo os outros, mas nós somos também esses outros e outros "outros".

Por vezes, quando nós nos explicamos, pensando que explicamos os outros, falamos coisas próximas daqueles que queremos explicar. Mesmo assim, ainda somos os sujeitos explicados em nossas explicaçōes. Somos caçacaçador. E com essas explicaçóes nos aproximamos das explicações dos outros. Assim:

- Eu penso o cotidiano enquanto me penso...

- Eu faço parte desse cotidiano que eu penso... Eu também sou esse cotidiano...

- Eu não penso "sobre" o cotidiano, eu penso "com" o cotidiano...

- Esses momentos, movimentos, processos, tentativas, possibilidades, de pensar "com" os cotidianos, de me pensar, possibilitam que eu me conheça ao mesmo tempo em que busco conhecer os outros...

- Mas, eu também sou esses outros...

- Sou todos aqueles que ali estão e também aqueles que já não estão...

- Sou parte ausente de uma história passada recontada pelos sujeitos de hoje...

- Mas também sou parte de uma história presente ainda por ser contada pelos que virão...

Outra idéia que nos parece fundamental nas pesquisas com o cotidiano tem a ver com a dimensão "do lugar", "do habitado", "do praticado", "do vivido", "do usado", como defendem Certeau (1994, 1996), Augé (1997), Lefebvre (1991) e outros. Ou seja, os estudos com o cotidiano das escolas acontecem em meio às situações do dia-a-dia, por entre fragmentos das vidas vividas. Mostram-se por meio de indícios (Ginzburg, 1989) efêmeros, pistas do que está, de fato, sendo feitopensadofalado pelos sujeitos cotidianos.

Os estudos com o cotidiano, ao acontecerem em meio ao que está sendo feito, isto é, em meio aos processos de tessitura e contaminação das redes, expressam o "entremeado" das relações dessas redes nos diferentes espaçostempos vividos. Augé (1994, p. 40-41) destaca essa dimensão da análise das singularidades ao afirmar: 
Além do peso maior dado, hoje, à referência individual, ou, se preferirem, à individualização das referências, é aos fatos de singularidade que se deveria prestar atenção: singularidade dos objetos, singularidades dos grupos ou das pertinências, recomposição de lugares, singularidades de toda ordem, que constituem o contraponto paradoxal dos processos de relacionamento, de aceleração e de deslocalização muito rapidamente reduzidas e resumidas, às vezes, por expressões como "homogeneização" - ou mundialização - da cultura.

Essa dimensão do que é, de fato, realizadopensadofalado no miudinho dos cotidianos das escolas permite-nos, como sujeitopesquisador, além de poder afirmar que o local tem importância (Ferraço, 2001), poder nos assumir como pertencentes a diferentes redes que expressam o entremeado desses saberesfazeres cotidianos, associados aos diferentes espaçostempos vividos pelos sujeitos. Os fluxos desses saberesfazeres por entre essas redes e seus sujeitos se dão em meio ao acaso das lógicas rizomáticas (Deleuze \& Guattari, 1995) que os caracterizam.

Isso posto, o fato de situarmos nosso estudo nessa dimensão das singularidades dos acontecimentos e dos sujeitos cotidianos não significa um reducionismo da complexidade requerida pelas questôes afins aos currículos praticados ou realizados, ou à formação continuada.

Neste sentido, há dois aspectos que precisam ser considerados. O primeiro deles coloca-nos a necessidade de essa análise privilegiar os saberespráticas dos sujeitos cotidianos, assumidos como sujeitos complexos e encarnados (Najmanovich, 2001), sob pena de cairmos em situações e textos artificiais, hipotéticos, de simulação da realidade vivida. Para tanto, evocamos Najmanovich (op. cit., p. 93-94):

O sujeito, desde a perspectiva das ciências da complexidade, é uma "unidade heterogênea”, organização emergente da interação de suborganizaçōes entre as quais se destacam a cognição, a emoção e a ação, que são as formas de interação do sujeito com o mundo. "O sujeito não é um ser, uma substância, uma estrutura ou uma coisa senão um devir nas interações".

O sujeito não é o dado biologicamente, mas o construído no intercâmbio em um meio social humano, que por sua vez está em interação constante com outros contextos. É através dos vínculos sociais de afeto, de linguagem, de comportamentos que o sujeito vai se auto-organizando. Agora, não devemos confundir o sujeito com a "subjetividade". "Esta é a forma peculiar que adota o vínculo humano-mundo em cada um de 
nós, é o espaço de liberdade e criatividade, o espaço da ética. Mas o sujeito não é somente onde se assenta a subjetividade, senão uma organização complexa capaz também de objetivar, quer dizer, de se compor, de estabelecer acordos no seio da comunidade, de produzir um imaginário comum e, portanto, de construir sua realidade". O que os positivistas chamam de 'o mundo objetivo' é para as ciências da complexidade uma realidade construída a partir de um imaginário social compartilhado por esses sujeitos que são parte indissociável desse mundo. "O mundo em que vivemos é um mundo humano, mundo simbólico, mundo construído em nossa interação com o real, com o que está fora da linguagem, com o mistério que opõe resistência às nossas criaçôes e ao mesmo tempo é a condição de suas possibilidades".

O segundo aspecto nos é dado pela discussão de Oliveira (2003, p. 57-58) com relação a Santos (2000) sobre as escalas de leitura de mundo e suas articulaçôes, ao observar que,

Partindo das regularidades e permanências captadas nos estudos globalizantes realizados através de "mapas em pequena escala", podemos construir os modelos, mas os modos como as realidades locais expressam as normas e as modificam pelas suas especificidades só podem ser compreendidos se "descemos" às singularidades, só perceptíveis nos mapas em "grande escala". Mais que isso, acredito que estudar o cotidiano contribui para a compreensão do processo através do qual os aspectos comuns compartilhados por práticas sempre distintas são transformados pelas exigências de organização e de busca de regularidades colocadas pelo pensamento totalizante, em modelos constituídos pelos pontos de interseção nos conjuntos das práticas.

Nesses processos de tessitura e contaminação entre as redes de saberesfazeres dos sujeitos praticantes dos cotidianos das escolas em um mapa de grande escala (Santos, ibid.), é que temos situado nossos temas de pesquisa. Dessa forma, estamos, em nossos estudos, envolvidos, mergulhados em movimentos de invenções e partilhas desses saberesfazeres, com destaque para artes de inventar o cotidiano (Certeau, 1994). Para esta possibilidade de mergulhar no cotidiano por ocasião da pesquisa, Alves (1998, p. 2) afirma:

O modo de "ver" dominante no mundo moderno deverá ser superado por um "mergulho" com todos os sentidos no que desejamos estudar; a este "mergulho" temos chamado, pedindo licença ao poeta Drumond, de "o sentimento do mundo"... Querer saber mais, buscando respeitar aquilo que 
Lefebvre chama de "a humilde razão do cotidiano", exige do/a pesquisador/a a isto dedicado que se ponha a sentir o mundo e não só a olhá-lo, soberbamente, do alto. Não há para nós a postura de isolamento da situação possível a outra postura epistemológica (...). Não há outra maneira de se compreender a lógica do cotidiano senão sabendo que nela estamos inteiramente mergulhados (...). Buscar entender, de maneira diferente do aprendido, as atividades do cotidiano escolar ou do cotidiano comum, exige que estejamos dispostos a ver além daquilo que os outros já viram e muito mais: que sejamos capazes de mergulhar inteiramente em uma determinada realidade buscando referências de sons, sendo capazes de engolir sentindo variedades de gostos, caminhar tocando coisas e pessoas e se deixando tocar por elas, cheirando os cheiros que a realidade vai colocando a cada ponto do caminho diário.

Nosso mergulho no cotidiano das escolas vai ao encontro, então, dessas redes de fazeressaberes e dos sujeitos protagonistas de histórias cotidianas que inventam a educação. Neste sentido, nos é de grande ajuda a discussão de Certeau \& Giard (1996, p. 341-342), com relação ao que chamam de cultura ordinária. Para eles,

(...) a cultura ordinária oculta uma diversidade fundamental de situações, interesses e contextos, sob a repetição aparente dos objetos de que se serve. A "pluralização" nasce do uso ordinário, daquela reserva imensa constituída pelo número e pela multiplicidade das diferenças (...). Neste sentido, a cultura ordinária é antes de tudo uma "ciência prática do singular", que toma às avessas nossos hábitos de pensamento onde a racionalidade científica é conhecimento do geral, abstração feita do circunstancial e do acidental. À sua maneira humilde e obstinada, a cultura ordinária elabora então o processo do nosso arsenal de procedimentos científicos e de nossas categorias epistêmicas, pois não cessa de rearticular saber a singular, de remeter um e outro a uma situação concreta particularizante e de selecionar seus próprios instrumentos e suas técnicas de uso em função desses critérios.

Outro aspecto abordado pelos autores e, de certo modo, anunciado anteriormente por nós remete-nos às limitações que enfrentamos nas análises dessa cultura ordinária dos sujeitos cotidianos.

Conhecemos mal os tipos de operações em jogo nas práticas ordinárias, seus registros e suas combinações porque nossos instrumentos de análise, de modelização e de formalização foram constituídos para outros objetos e com outros objetivos. O essencial do trabalho de análise que deveria ser feito deverá inscrever-se na análise combinatória sutil, de tipos de operações e de registros, que coloca em cena e em ação um fazer-com, aqui e 
agora, que é um ato singular ligado a uma situação, circunstâncias e atores particulares (...). Nossas categorias de saber ainda são muito rústicas e nossos modelos de análise por demais elaborados para permitir-nos imaginar a incrível abundância inventiva das práticas cotidianas. É lastimável constatá-lo: quanto nos falta ainda compreender dos inúmeros artifícios dos "obscuros heróis" do efêmero, andarilhos da cidade, moradores dos bairros, leitores e sonhadores, pessoas obscuras das cozinhas. Como tudo isso é admirável. (Certeau \& Giard, 1996, p. 341-342)

Como tentativa de superar o problema colocado anteriormente, de engessamento da vida cotidiana por meio do uso de categorias, estruturas ou classificações que, fatalmente, simplificam a diversidade e complexidade dessa cultura ordinária dos sujeitos cotidianos, temos buscado, em autoras como Nilda Alves, outras alternativas metodológicas para a pesquisa com o cotidiano. Neste sentido, destacamos, num primeiro momento, a proposta sistematizada pela autora (2001, p. 14-16) no livro Pesquisa noldo cotidiano:

Defendo, e não estou sozinha, que há um modo de fazer e de criar conhecimento no cotidiano, diferente daquele aprendido, na modernidade, especialmente, e não só, com a ciência.

São quatro os aspectos que julgo necessário discutir para começar a compreender essa complexidade. O primeiro deles se refere [ao fato de que] a trajetória de um trabalho no cotidiano precisa ir além do que foi aprendido com as virtualidades da modernidade, na qual o sentido da visão foi exaltado. É preciso executar um mergulho com todos os sentidos no que desejo estudar. Pedindo licença ao poeta Drummond, tenho chamado esse movimento de o sentimento do mundo.

O segundo movimento a ser feito é compreender que o conjunto de teorias, conceitos e noçôes que herdamos das ciências criadas e desenvolvidas na chamada modernidade e que continuam sendo um recurso indispensável, não é só apoio e orientador da rota a ser trilhada, mas, também e cada vez mais, limite ao que precisa ser tecido. Para nomear esse processo (...) estou usando a idéia de virar de ponta-cabeça.

Para ampliar os movimentos necessários, creio que o terceiro deles, incorporando a noção de complexidade, vai exigir a ampliação do que é entendido como fonte e a discussão sobre os modos de lidar com a diversidade, o diferente e o heterogêneo. Creio poder chamar a esse movimento de beber em todas as fontes.

Por fim, vou precisar assumir que para comunicar novas preocupações, novos problemas, novos fatos e novos achados é indispensável uma nova maneira de escrever, que remete a mudanças muito mais profundas. A 
esse movimento talvez se pudesse chamar de narrar a vida e literaturizar a ciência.

Dentre os movimentos propostos por Alves, queremos destacar o uso de narrativas como possibilidades que temos encontrado, nas pesquisas com os cotidianos das escolas, de uma aproximação menos estruturante, menos edificante para a vida ali vivida e, por conseqüência, como possibilidades de expressão das redes tecidas nessas vidas.

De fato, as narrativas a que temos tido acesso, dos sujeitos praticantes do cotidiano das escolas pesquisadas, têm se revelado muito mais como potencialidades de expressões dos enredamentos, dos fluxos, das redes, do que, de fato, como descrição e/ou identificação do fato acontecido tal e qual aconteceu. As narrativas envolvem, ao mesmo tempo, diferentes lugares praticados pelos sujeitos narradores e diferentes relações de fazeressaberes desses narradores praticantes que são. A esse respeito, Alves e Garcia (2002, p. 274-277) observam:

Parece-nos necessário observar que a narratividade, a história narrada, não significa um retorno à "descrição" que marcou a historicidade na época clássica, pois, ao contrário dessa, não há na primeira a "obrigação" de se aproximar da "realidade", mas sim de criar um espaço de ficção, aparentemente se subtraindo à conjuntura ao dizer: "era uma vez...".

É preciso, pois, que incorporemos a idéia de que, ao dizer uma história, somos "narradores praticantes" traçando/trançando as redes dos múltiplos relatos que chegaram/chegam até nós, neles inserindo, sempre, o fio do nosso modo próprio de contar [g.n.]. Exercemos, assim, a "arte de contar histórias", tão importante para quem vive o cotidiano do aprenderensinar. Buscamos acrescentar ao grande prazer de contar histórias, o também prazeroso ato da pertinência do que é científico. É possível? Bem, se outros e outras fizeram antes de nós e continuam fazendo, por que não? (...).

Defendemos ser possível dialogar com o cotidiano da escola dentro de sua própria "música", com a inventividade e as repetiçóes que comporta. Mas, para isso, precisamos contá-lo a partir de relatos orais que são, em tudo, diferentes das fontes escritas (...).

Então, trabalhar com narrativas coloca-se para nós como uma possibilidade de fazer valer as dimensões de autoria, autonomia, legitimidade, beleza e pluralidade de estéticas dos discursos dos sujeitos cotidianos. Trabalhar com histórias narradas mostra-se como uma tentativa de dar visibilidade a esses sujeitos, afirmando-os como autoresautoras, também protagonistas dos nossos estudos. 
Mesmo com todo o empenho e a determinação de pesquisadores comprometidos, como sujeitosindividuaiscoletivos que se pensam "com" os cotidianos, ainda somos nós, alguns poucos, que decidimos que fios, que lembranças, que relatos, que imagens, que histórias, que sons, sombras e silêncios se tornarão "visíveis" aos "olhos" dos nossos leitores. Somos alguns poucos que, ao ousar "invadir" os cotidianos das escolas na tentativa de falar aos que ainda não se deram conta de que nada lá é lugar-comum, repetição ou obviedade, acabaremos por decidir quais serão as "marcas" dos cotidianos a serem impressas em nossos textos.

Então, para que a pena nos seja leve, precisamos assumir nossos limites, amarras e impossibilidades não como problemas, mas como condiçôes necessárias aos estudos "com" os cotidianos. Ainda aqui, precisamos assumir nossos textos em sua permanente condição de "discursos inacabados". O presente texto revela essa condição. Não se trata, ainda, de um estudo "com" os cotidianos das escolas. Mais uma vez, acabou por ser um texto "sobre" os cotidianos das escolas, apesar da nossa própria crítica.

Portanto, para que a pena continue leve, nessa tentativa de dar conta de nós mesmos e dos outros nos nossos estudos, precisamos pensar em possibilidades de discursos que possam registrar os pensamentos e as palavras que transbordam por paredes e corredores das escolas e que nem sempre são ditas. Discursos que precisam incluir outros discursos, alternativos, e que apostam sempre nas suas próprias explicações. Discursos que ficam à espreita, esperando capturar microdiferenças que marcam as sutilezas das falas, dos gestos e das imagens que habitam os cotidianos. Discursos que tentam traduzir os idiomas e os modos de ser e existir dos sujeitos cotidianos em cujos corpos encontramos registradas as marcas dos usos e das transgressóes. Discursos que têm olhos distraídos que deixam de ver outras tantas coisas além daquelas que foram tornadas visíveis. Discursos que, apesar do nosso olhar congelador, precisam dar conta das identidades movediças, dos hibridismos.

Discursos que, por mais vivos que possam parecer aos olhos dos leitoresleitoras, ainda estão muito longe de captar toda a intensidade da vida cotidiana. Os cotidianos estão pulsando muito mais fortemente do que qualquer análise que façamos "com" eles.

Discursos que nos angustiam pelos vazios que são deixados por entre as linhas escritas porque não há palavras que possam dar conta 
do que estamos querendo dizer naquele momento, como acontece com o autor deste texto, agora.

\section{Algumas pistas dos sujeitos praticantes em nossas pesquisas com o cotidiano}

Nossas conversas com os sujeitos das escolas nos têm levado a pensar nos currículos praticados e na formação continuada para além dos seus contextos teóricos imediatos. De fato, as escolas articulam-se com outros grupos sociais, com outros espaçostempos institucionais, por intermédio das redes de relações formais e informais que ligam seus sujeitos, e que os levam a assumir diferentes saberesfazeres na invenção do cotidiano, muitas vezes opondo-se às políticas oficiais impostas às escolas.

Essas relaçôes tecidas em redes criam, nas escolas, ambientes movediços, entre-lugares da cultura, processos instituintes que possibilitam aos sujeitos praticantes viverem suas dimensôes de hibridização (Bhabha, 1998). Ao discutir a idéia de entre-lugar da cultura Bhabha (op. cit., p. 20-21) observa que,

Os termos do embate cultural, seja através de antagonismo ou afiliação, são produzidos performativamente. A representação da diferença não deve ser lida apressadamente como o reflexo de traços culturais ou éticos "preestabelecidos", inscritos na lápide fixa da tradição. A articulação social da diferença, da perspectiva da minoria, é uma negociação complexa, em andamento, que procura conferir autoridade aos hibridismos culturais que emergem em momentos de transformação histórica.

O reconhecimento que a tradição outorga é uma forma parcial de identificação. Ao reencenar o passado, este introduz outras temporalidades culturais incomensuráveis na invenção da tradição. Esse processo afasta qualquer acesso imediato a uma identidade original ou a uma tradição "recebida".

Assim, como sujeitos híbridos que somos e praticando saberesfazeres nesses entre-lugares da cultura que também são as escolas, os sujeitos cotidianos inventam currículos e processos de formação continuada que, como no dizer de Bhabha, não se deixam aprisionar por identidades culturais (ou políticas), originais ou fixas.

Os embates de fronteira acerca da diferença cultural têm tanta possibilidade de serem consensuais quanto conflituosos; podem confundir nossas defini- 
ções de tradição e modernidade, realinhar as fronteiras habituais entre o público e o privado, o alto e o baixo, assim como desafiar as expectativas normativas de desenvolvimento e progresso. (1998, p. 21).

Nesses embates de fronteira acerca da diferença cultural são realizados processos de tradução. Neste sentido, Bhabha (s/d., p. 36) considera que

A diferença de culturas não pode ser uma coisa para ser encaixada numa moldura universalista. Culturas diferentes, a diferença entre as práticas culturais, a diferença na construção de culturas dentro de grupos diferentes, com grande freqüência fazem existir no seu meio, e entre elas próprias, uma incomensurabilidade. Por mais racional ou "racionalista" que alguém seja (pois o racionalismo é uma ideologia, não apenas um modo de ser sensato), na realidade é muito difícil, e até mesmo contraproducente e impossível, tentar e conseguir juntar diferentes formas de cultura, pretendendo que elas possam coexistir facilmente.

Tanto o relativismo quanto o universalismo têm suas formas radicais, que podem ser mais atraentes, mas até estas fazem parte basicamente de um mesmo processo. Neste ponto eu gostaria de apresentar a noção de "tradução cultural" para sugerir que todas as formas de cultura estão de algum modo relacionadas umas com as outras, porque cultura é uma atividade significante ou simbólica. A articulação de culturas é possível não por causa da familiaridade ou similaridade de conteúdos, mas porque todas as culturas são formadoras e constituidoras de temas - são práticas interpelantes. (...) Nenhuma cultura é completa em si mesma, nenhuma cultura se encontra a rigor em plenitude...

Por tradução eu me refiro, antes de tudo, a um processo pelo qual, a fim de objetivar o sentido cultural, é forçoso haver sempre um processo de alienação e de secundariedade em relação a si próprio. Sob esse aspecto, não há "em si mesmo" nem "por si mesmo" no interior das culturas, porque elas sempre estão sujeitas a formas intrínsecas de tradução. Desenvolvendo essa noção, a tradução é também uma maneira de imitar, mas num sentido traiçoeiro e deslocante - o de imitar um original de tal modo que a sua prioridade não é reforçada e sim, pelo próprio fato de ele poder ser simulado, reproduzido, transferido, transformado, tornado um simulacro e assim por diante: nunca o original se conclui ou se completa em si mesmo.

Assim, os diferentes processos de tradução cultural possibilitam o surgimento de costumes locais, na maioria das vezes compartilhados, mas que não são uniformes nem definitivos. Ainda aqui, há de se des- 
tacar que, em meio às redes, as individualidades híbridas buscam ser preservadas. Não se trata de homogeneidades indiferenciadas, suprimidas ou reprimidas pelo coletivo ou pela busca de uma essência. Os sujeitos individuaiscoletivos, cada um a seu modo, deixam suas marcas com os seus fazeressaberes.

As redes tecidas em meio à articulação dos contextos culturais, políticos, sociais, econômicos, religiosos, familiares, vividos pelos sujeitos cotidianos, produzem diferentes saberesfazeres dependendo de necessidades e/ou interesses pessoais e/ou locais, das histórias de vida, formações, valores e intenções.

Com isso, os saberesfazeres que os sujeitos praticam nos cotidianos escolares não são definidos apenas institucionalmente, de acordo com as normas decorrentes da lógica hierárquica de funções e/ou formações. A visão estrutural-funcionalista prescritiva, que normalmente define essas práticassaberes, é superada a partir das relações de saberpoder que se dão nas redes locaisglobais. Como já dito, as práticassaberes que se tecem em redes apontam para a caracterização de sujeitos híbridos, sem qualquer possibilidade de uma perspectiva de essência destes.

Outro aspecto a ser destacado, do ponto de vista do currículo e da formação que se realizam nos cotidianos das escolas, mostra-nos que, em meio às redes e aos contextos vividos, os diferentes saberespráticas têm na relação solidária (Maturana \& Varela, 1995) sua expressão mais visível. $\mathrm{O}$ currículo e a formação continuada assumidos em meio às redes tecidas estão encharcados de relaçôes que advogam em favor dos princípios de coletividade e solidariedade. Ao contrário da lógica que estimula e valoriza práticas individualistas e de competição, as redes tecidas e compartilhadas pelos sujeitos no cotidiano das escolas nas quais as pesquisas aconteceram apontam para ações coletivas que são realizadas com o fim de se buscar saídas para os problemas enfrentados. Não há imobilismo. Há resistência.

Assim, nas invenções dos currículos e dos processos de formação continuada há, entre esses sujeitos cotidianos, processos auto-organizativos espontâneos, impossíveis de serem desconsiderados ou subestimados. Em nossas vivências nos cotidianos das escolas pudemos compreender que, sobretudo, também são em meio a essas relaçôes que se auto-organizam que os saberesfazeres são inventados pelos sujeitos.

Se a força e a beleza do cotidiano das escolas estão nas redes que têm no coletivo sua expressão máxima (apesar de as marcas do individu- 
alismo também se fazerem presentes), e os processos pedagógicos configuram-se como auto-organizativos então, é para e com os sujeitos como expressões desse coletivo que têm de ser pensadas e realizadas as ações e propostas políticas que pretendam transformaçōes significativas.

Nas redes de relações e ações vividas nos cotidianos das escolas, raras as ocasiōes em que são tomadas atitudes que podem ser explicadas de forma pontual, isolada dessas redes. Os sujeitos dos cotidianos das escolas nos têm ensinado que, nas redes cotidianas, o eu só se produz, só se constitui nas relaçóes com o outro.

As redes cotidianas estão encharcadas de ajudas e pactos. Estão atravessadas por diversos processos instituintes. Então, são nesses processos coletivos que devemos prestar atenção no sentido de participar, ajudar e intervir. São nas práticas instituintes realizadas pelos seus coletivos que as escolas revelam suas energias e utopias políticas.

De fato, os fazeressaberes coletivos dos sujeitos das escolas estão, o tempo todo, atravessados por questões políticas e, neste sentido, têm mostrado que as possibilidades de transformação e luta estão sempre colocadas, estão presentes nesses cotidianos das escolas, não necessariamente sendo assumidas com a mesma intensidade pelos sujeitos. Neste sentido, valeria a reflexão que nos propõe Lefebvre (1991, p. 21-22):

"Ou" empregamos nossas energias práticas, para fortificar as instituições, as ideologias existentes - o estado ou uma igreja, um sistema filosófico ou uma organização política - e ao mesmo tempo nos empenhamos em consolidar o cotidiano sobre o qual se estabelecem e se mantêm essas "superestruturas"; "ou" nos dedicamos a "mudar a vida". Em outras palavras, "ou" erigimos em absolutos, em idéias platônicas as instâncias que se elevam acima do cotidiano com a pretensão de regê-lo - "ou então" tornamos relativas essas entidades, recusamos substancializar, desvalorizamolas, valorizando o que elas depreciam e sobre o qual elas pesam, considerando-o nada mais que um resíduo: o cotidiano. "Ou" trabalhamos para esmagar esse residual, "ou" consideramos o irredutível, o preciso conteúdo das formas abstratas e das diferenças concretas. "Ou" nos colocamos a serviço das "causas", "ou" ajudamos a humilde razão do cotidiano.

Por fim, como já destacado, também buscamos discutir a impossibilidade de se pensar, de se pesquisar as redes cotidianas de saberesfazeres fora dos espaçostempos cotidianos e dos sujeitos que praticam esses espaçostempos. Ou seja, essas pesquisas não podem assumir essas redes como mo- 
delos ou teorias externas aos cotidianos, mas precisam assumi-las em sua condição de existência efêmera nos movimentos diários.

Neste sentido, os sujeitos cotidianos, a cada dia, inventam-se e, ao se inventarem, inventam a escola. Por isso não há repetição, não há mesmice. A rotina é algo que se realiza a cada dia de forma diferente e que se expressa nas tentativas de enfrentamentos das questóes que se colocam nas escolas. A cada dia, há outras questões e outros enfrentamentos, com a marca da humildade dos praticantes, ao assumirem que não podem e não conseguem controlar tudo e todos ao mesmo tempo, cientes de que a lógica determinista e causal não lhes possibilita uma ação que rompa com as estruturas que aprisionam a vida na escola.

Pelo contrário, nas saídas inventadas, diante dos impasses vividos, os sujeitos cotidianos das escolas sabem que são muitas e diferentes as inseguranças, os desafios, as dúvidas, os caminhos e atalhos a serem trilhados. Isso porque não há uma única lógica que rege esses processos, mas há diferentes possibilidades de lógicas. Alves \& Oliveira $(1998$, p. 1) falam dessas lógicas ao se referirem à questão dos valores. Segundo as autoras:

A multiplicidade e a complexidade de relações, no caso da escola, entre cotidiano, conhecimento e currículo vai nos exigir, de início, a incorporação das noções de redes de conhecimentos e de tessitura do conhecimento em rede, na compreensão de que estamos, permanentemente imersos em redes de contatos diversos, diferentes e variados nas quais criamos conhecimentos e que, neste cotidiano, tecemos nossos conhecimentos com os conhecimentos de outros seres humanos, permitindo, assim, a produção de outros conhecimentos em redes. Dessa maneira, não só não podemos identificar todas as origens de nossos tantos conhecimentos, como eles só podem começar a ser explicados se nos dedicarmos a perceber as intrincadas redes nas quais são verdadeiramente enredados. Se vamos investigar, por exemplo, os valores, estes conhecimentos especiais com os quais orientamos nossas ações, especialmente em seu aspecto negativo - os preconceitos -, quase que com certeza não conseguiremos (e mais comumente, não poderemos, pelas mesmas múltiplas questôes que lhes facilitaram o aparecimento) identificar em que intrincadas redes de relaçôes cotidianas os fomos criando e firmando, transformando-os em "verdades" orientadoras. Por isso mesmo é que para identificar, caracterizar, analisar e, no exemplo dado, superar estes conhecimentos "verdadeiros", será preciso trabalhar com suas próprias lógicas, o que exige muito trabalho já que tão pouco delas conhecemos. 
Assim, é preciso que possamos buscar entender essas lógicas, buscar apreender alguns de seus fragmentos, como tentativa de análise e/ou intervenção na vida cotidiana. Neste sentido, o paradigma indiciário proposto por Carlo Ginzburg (1989) tem sido, em nossas pesquisas, de fundamental importância, sobretudo pela impossibilidade, a partir das pistas encontradas no cotidiano, de usarmos as palavras no singular para nos referirmos à diversidade encontrada.

\section{Recebido em outubro de 2006 e aprovado em março de 2007.}

\section{Notas}

1. O texto condensa discussões das pesquisas "Currículo e formação de educadores" e "Pensando os currículos prescritos e a formação continuada de educadores do Ensino Fundamental a partir dos currículos reais", por nós realizadas em escolas públicas da Rede Estadual do Espírito Santo e das Redes Municipais de Cariacica, Ecoporanga, Jaguaré, São Mateus, Vargem Alta e Vitória, localizadas no referido estado.

2. Usaremos, alternadamente, os gêneros masculino e feminino.

3. No decorrer do texto voltarei a falar dos/nos sujeitos das escolas.

4. Nossas leituras têm percorrido diferentes autores que têm se dedicado à questão do cotidiano, entre os quais destacamos: Agnes Heller, Boaventura de Sousa Santos, Georg Lukács, Henri Lefebvre, Inês Barbosa de Oliveira, Joanir Gomes de Azevedo, José Machado Pais, Maria Teresa Esteban, Michel de Certeau, Nilda Alves, Paulo Sgarbi e Regina Leite Garcia.

\section{Referências bibliográficas}

ALVES, N. O espaço escolar e suas marcas. Rio de Janeiro: DP\&A, 1998.

ALVES, N. Decifrando o pergaminho: o cotidiano das escolas nas lógicas das redes cotidianas. In: Oliveira, I.B.; Alves, N. (Org.). Pesquisa noldo cotidiano das escolas: sobre redes de saberes. Rio de Janeiro: DP\&A, 2001.

ALVES, N.; GARCIA, R.L. A necessidade da orientação coletiva nos estudos sobre cotidiano: duas experiências. In: BiAnCHETTI, L.; MACHADo, A.M.N. (Org.). A bússola do escrever. São Paulo: Cortez; Florianópolis: UFSC, 2002. p. 255-296.

ALVES, N.; OLIVEIRA, I.B. Pesquisar o cotidiano na lógica das redes cotidianas. In: REUNIÃO ANUAL DA ANPED, 21., 1998, Caxambú. Anais... Caxambú, 1998. (minicurso) 
AUGÉ, M. Não-lugares. São Paulo: Papirus, 1994.

AUGÉ, M. Por uma antropologia dos mundos contemporâneos. Rio de Janeiro: Bertrand Brasil, 1997.

BHABHA, H. O local da cultura. Belo Horizonte: UfmG, 1998.

BHABHA, H. O terceiro espaço. Revista do Patrimônio Histórico e Artístico Nacional, Rio de Janeiro, s.d.

CERTEAU, M. A invenção do cotidiano 1: as artes de fazer. Petrópolis: Vozes, 1994.

CERTEAU, M. A invenção do cotidiano 2: morar, cozinhar. Petrópolis: Vozes, 1996.

CERTEAU, M.; GIARD, L. Uma ciência prática do singular. In: Certeau, M. A invenção do cotidiano 2: morar, cozinhar. Petrópolis: Vozes, 1996.

DELEUZE, G.; GUATTARI, F. Mil platôs. São Paulo: Editora 34, 1995. v.1.

FERRAÇO, C. E. Ensaio de uma metodologia efêmera: ou sobre as várias maneiras de se sentir e inventar o cotidiano escolar. In: OliveirA, I.B.; Alves, N. (Org.). Pesquisa no/do cotidiano das escolas: sobre redes de saberes. Rio de Janeiro: DP\&A, 2001. p. 91-108.

FERRAÇO, C.E. Eu, caçador de mim. In: GarCIA, R.L. (Org.). Método: pesquisa com o cotidiano. Rio de Janeiro: DP\&A, 2003.

GINZBURG, C. Mitos, emblemas e sinais. São Paulo: Cia das Letras, 1989.

LEFEBVRE, H. A vida cotidiana no mundo moderno. São Paulo: Ática, 1991.

LINHARES, C.; GARCIA, R.L. Simpósio Internacional Crise da Razão e Crise da Politica na Formação Docente. Rio de Janeiro: Ágora da Ilha, 2001.

MATURANA, H.; VARELA, F. A árvore do conhecimento. Campinas: Psy, 1995. 
MONTEIRO, J.M.N.B. Retalhos de vida: ou sobre tessituras na formação continuada. 2003. Dissertação (Mestrado) - Universidade Federal do Espírito Santo (UFES), Vitória.

MORIN, E. Introdução ao pensamento complexo. Lisboa: Instituto Piaget, 1990.

MORIN, E. O problema epistemológico da complexidade. Sintra: M. Martins, 1994.

NAJMANOVICH, D. O sujeito encarnado: questōes para pesquisa no/do cotidiano. Rio de Janeiro: DP\&A, 2001.

OLIVEIRA, I.B. Currículos praticados: entre a regulação e a emancipação. Rio de Janeiro: DP\&A, 2003.

SACRISTÁN, G. Currículo e diversidade cultural. In: Silva, T.T.; Moreira, A.F. (Org.). Territórios contestados. Petrópolis: Vozes, 1995.

SANTOS, B.S. A crítica da razão indolente: contra o desperdício da experiência. São Paulo: Cortez, 2000. 